\title{
An observational study to determine accuracy of various methods used to assign gestational age and correlate with outcome
}

\author{
Neha Singhal*, Alka S. Gupta
}

Department of Obstetrics and Gynecology, Seth G.S. Medical College and KEM Hospital, Mumbai, Maharashtra, India

Received: 12 July 2018

Accepted: 06 August 2018

*Correspondence:

Dr. Neha Singhal,

E-mail: nehasinghal.doc@gmail.com

Copyright: (C) the author(s), publisher and licensee Medip Academy. This is an open-access article distributed under the terms of the Creative Commons Attribution Non-Commercial License, which permits unrestricted non-commercial use, distribution, and reproduction in any medium, provided the original work is properly cited.

\section{ABSTRACT}

Background: Appropriate estimation of gestational age is paramount in obstetric care. Uncertain gestational age may lead to adverse pregnancy outcome like low birth weight, spontaneous or iatrogenic preterm delivery and perinatal mortality independent of maternal characteristics. In India, seeking of early medical attention in pregnancy is still not the norm. Three methods to estimate the estimated date of delivery are available, namely, menstrual history, clinical examination and by ultrasound. This study attempts to analyse the accuracy of the three methods used and their correlation with maternal and fetal outcome.

Methods: 260 patients presenting to the outpatient department were enrolled irrespective of the gestational age but as soon as they got registered. Ultrasonography was advised if the patient did not have one. EDD was calculated by various methods and was recorded. If significant discrepancy existed, EDD was reassigned. Patients were followed up till the time of their delivery. After the delivery of the baby gestational age was assessed by the neonatologist and was compared with the gestational age at the time of delivery by the three methods. Maternal and fetal outcomes were compared in the form of avoided inductions and maturity of the baby at the time of delivery by all the three methods.

Results: The kappa coefficient for the agreement between dating by ultrasound scan and neonatologist was 0.415 whereas for menstrual dates and clinical examination it was 0.197 and 0.369 respectively thus it can be interpreted that the accuracy of ultrasonography may be slightly better than menstrual dates and clinical examination. 75 patients required reassigning of EDD, Induction of labor for supposed post-term pregnancy was avoided in $13 \%$ of the patients.

Conclusions: Ultrasonography was found to be accurate for determination of term /preterm/ post-term births followed by clinical examination and then the menstrual EDD. Induction of labor for supposed post-term pregnancy was avoided in $13 \%$ of the patients in whom EDD was "assigned" thus stressing that EDD should be reassigned when there is discrepancy between menstrual EDD, Ultrasonography EDD and EDD by clinical examination.

Keywords: Gestational age, EDD, Ultrasound

\section{INTRODUCTION}

Appropriate estimation of gestational age is paramount in obstetric care. Uncertain gestational age may lead to adverse pregnancy outcome like low birth weight, spontaneous or iatrogenic preterm delivery and perinatal mortality independent of maternal characteristics. ${ }^{1}$ The cost of management of preterm deliveries is also huge. ${ }^{2} \mathrm{~A}$ lot of emphasis has been made on finding techniques to avoid preterm births. ${ }^{3}$ However, more than prevention of preterm birth, accurate identification of gestational age is the first step. To make appropriate management decisions and to deliver good obstetric care requires an accurate appraisal of gestational age, which is sometimes 
trivialised and looked down upon. If gestational age is accurately measured, unnecessary testing such as fetal monitoring and unwarranted interventions including induction for supposed post-term pregnancy may be avoided. Similarly, unnecessary hospitalization stays and potentially dangerous medication use including tocolytic therapy for supposed preterm pregnancy can be avoided.

There are various methods for assessment of gestational age. These include usage of menstrual history, based on last menstrual period, clinical examination of the uterine size by bimanual pelvic examination during the first trimester and abdominal examination during the later gestations and ultrasonographic methods at various points in gestational age. Despite the availability of various such methods, the obstetricians are many times faced with challenges in the accurate dating of the pregnancy. This is because of prevalent practices among patients which include late- presentation for obstetric care and nonperformance of ultrasonography during the early gestational age. Enabudoso studied the determinants of gestational age at the time of booking in Africa. It was clearly proven that late booking for antenatal care is highly prevalent. Some factors which influence earlier booking are nulliparity and previous fetal loss. There exist a lot of missed opportunities for counselling and earlier diagnosis due to late booking. ${ }^{4}$ Moreover, even when these parameters are available, their accuracy independently is sometimes doubtful. In this context we designed this study to enhance our knowledge about the accuracy of these available methods for gestational determination.

\section{METHODS}

A prospective observational study was conducted in the Department of Gynaecology and Obstetrics in a teaching medical college hospital situated in urban India. Pregnant woman who came in the OPD in a particular unit were enrolled irrespective of the gestational age.

Exclusion criteria - Patient who doesn't remember their LMP, with multiple pregnancies, which chronic diseases like hypertensive and kidney diseases, ultrasonography showing congenital defects in the baby were excluded.

The sample size was calculated with the formula,

$\mathrm{n}=4 \mathrm{pqN} / \mathrm{e} 2(\mathrm{~N}-1)+4 \mathrm{pq}$

Using this formula and substituting $p$ =accuracy of menstrual estimated date of delivery (EDD) as compared to USG EDD, $\mathrm{q}=100-\mathrm{p}, \mathrm{N}=$ total number of confinements, $\mathrm{e}=10 \% \mathrm{p}+5 \%$, sample size turned out to be 260 .

Patients were enrolled in the study at any gestation age in pregnancy but as soon as they got registered. Patients' consent was taken to allow us to review their case records, check the accuracy of the assigned EDD.
Routine antenatal care was provided on antenatal outpatient basis and no management protocol was changed.

Thorough history was taken on 1 st contact with the patient and was recorded. If the patient came in the first trimester, the EDD was calculated by her menstrual history (using Naegle's rule), by bimanual examination, and first trimester ultrasonography was advised. She was asked to follow up after 4 weeks. At this visit, EDD by LMP and USG and uterine size determined by bimanual examination was matched and if the discrepancy with the USG dating was more than 5-7 days then accordingly her EDD was "reassigned" according to USG dating. Similarly, if the patient came in second trimester then EDD was calculated by her LMP, by SFH measurement, and second trimester sonography was done for dating as well as to rule out any congenital malformation. SFH was calculated in centimetre with a non-elastic measuring tape in the supine position after the woman had emptied her bladder.

Accordingly, if the discrepancy between the EDD by her LMP and USG was more than 7-14 days then her EDD was reassigned according to USG and clinical examination. If in case patient directly came in third trimester then her EDD was calculated by her LMP, by SFH measurement, and a third trimester USG was advised. But before her pregnancy was reassigned on the basis of USG, a repeat USG was seen to look for interval growth then if the discrepancy between the EDD by her LMP and USG differed by 21 days then her EDD was reassigned according to ultrasound dating. The methods studied to determine gestational age was LMP dating, clinical examination (bimanual examination or Leopold grips), SFH measurement) and the USG dating. The EDD was calculated for each of these methods using the gestational age obtained at enrolment. The calculations of expected date of delivery were based on the assumption that term delivery occurs at 40 weeks.

A preterm delivery is defined as a delivery occurring before the 37 th week and a term delivery as a delivery occurring between the beginning of 37 th week and the end of the 41 stweek (41 weeks and 6 days). A post-term delivery means delivery occurring in the 42 weeks or later. After the delivery of the baby dating of the gestational age was done by the neonatologists and was recorded in the case record form which was taken as the gold standard reference.

The patients were followed up till the time of their delivery and the following objectives were kept at the time of delivery.

- To determine the number of preterm, term and postterm deliveries by various methods and them comparing it with the gestational age assessed by the neonatologist 
- To determine accuracy of various methods used to assign gestational age.

- To study the correlation of maternal and fetal outcome in patients in whom gestational age was accurately dated and otherwise

\section{Statistical methods}

- Frequency tables

- Kappa test for correlation and inter-method consistency.

\section{RESULTS}

260 patients were enrolled. As shown in table 1, ninetynine patients in present study out of 260 had first trimester scan according to which preterm births were $12 \%$. The corresponding rate of preterm births, as determined by clinical examination was also $12 \%$. Considering such a high accuracy, it highlights that clinical examination should be done meticulously in the first trimester. In present study EDD was "Assigned" when there was discrepancy in menstrual EDD and USG dating.

Table 1: Term/preterm/post term delivery for those with available first trimester scan.

\begin{tabular}{|llll|}
\hline Methods & $\begin{array}{l}\text { Preterm } \\
(\%)\end{array}$ & $\begin{array}{l}\text { Term } \\
(\%)\end{array}$ & $\begin{array}{l}\text { Post-term } \\
(\%)\end{array}$ \\
\hline $\begin{array}{l}\text { First trimester } \\
\text { ultrasound sca }\end{array}$ & $12(12.1)$ & $87(87.8)$ & 0 \\
\hline LMP & $6(6.06)$ & $88(88.8)$ & $5(5.05)$ \\
\hline $\begin{array}{l}\text { Clinical } \\
\text { examination }\end{array}$ & $12(12.1)$ & $87(87.8)$ & 0 \\
\hline
\end{tabular}

From table 2, it is seen that out of 75 patients who required reassigning of $\mathrm{EDD}$, induction of labor for supposed post-term pregnancy was avoided in $13 \%$ of the patients.

Table 2: Term/preterm/post term in subgroup of patients in whom EDD was 'assigned'.

\begin{tabular}{|llll} 
& $\begin{array}{l}\text { Term } \\
(\%)\end{array}$ & $\begin{array}{l}\text { Preterm } \\
(\%)\end{array}$ & $\begin{array}{l}\text { Post-term } \\
(\%)\end{array}$ \\
\hline Assigned EDD & $61(81)$ & $14(19)$ & \\
Menstrual EDD & $55(73)$ & $10(13)$ & $10(13)$ \\
\hline
\end{tabular}

As shown in table 3, two hundred twenty-one (221) patients delivered at term gestation when calculated by menstrual history. When the dating of the newborn was done by the neonatologist it was found that 203 patients i.e. $91.9 \%$ was in agreement with the menstrual dates. Whereas 7 patients $(3.2 \%)$ who were considered to be term by dates were actually preterm by neonatal evaluation and 11(5\%) were post term by neonatal examination. Out of 28 patients delivered at preterm gestation as calculated by menstrual history, but only $9(32.1 \%)$ were determined to be preterm by the neonatologist. Out of 11 patients supposed to be postdated by the menstrual history, none of them were postdated when estimated by the neonatologist. This signifies that LMP may be reliable mainly to predict term births rather than post-term or preterm births. Among 224 patients who were considered term gestation by clinical examination,211 $(94.2 \%)$ were determined to be term by the neonatologist gestation. The remaining $10(4.5 \%)$ were post-dated and $3(1.3 \%)$ determined as preterm gestation.

Table 3: Correlation between menstrual dating and dating by Neonatologist.

\begin{tabular}{|lllll|}
\hline Menstrual & $\begin{array}{l}\text { Dating by } \\
\text { Preterm } \\
(\boldsymbol{\%})\end{array}$ & $\begin{array}{l}\text { Term } \\
(\boldsymbol{\%})\end{array}$ & $\begin{array}{l}\text { Post term } \\
(\boldsymbol{\%})\end{array}$ & $\begin{array}{l}\text { Total } \\
(\boldsymbol{\%})\end{array}$ \\
\hline Preterm & $9(32.1)$ & $19(67.9)$ & 0 & 28 \\
\hline Term & $7(3.2)$ & $203(91.9)$ & $11(5.0 \%)$ & 221 \\
\hline Post-term & 0 & $11(100.0)$ & 0 & 11 \\
\hline
\end{tabular}

Symmetric measurement of agreement (kappa); value $=0.197$, approx. T-4.084, $\mathrm{p}$ value $4.43 \mathrm{E}-05$ and agreement is significant.

Table 4: Correlation between dating by clinical examination and dating by neonatologist.

\begin{tabular}{|lllll|} 
& \multicolumn{2}{l}{$\begin{array}{l}\text { Dating by Neonatologist } \\
\text { (Weeks) }\end{array}$} & Total \\
Clinical & $\begin{array}{l}\text { Preterm } \\
(\mathbf{\%})\end{array}$ & $\begin{array}{l}\text { Term } \\
(\mathbf{\%})\end{array}$ & $\begin{array}{l}\text { Post term } \\
(\mathbf{\%})\end{array}$ & \\
\hline Preterm & $13(37.1)$ & $21(60.0)$ & $1(2.9)$ & 35 \\
\hline Term & $3(1.3)$ & $211(94.2)$ & $10(4.5)$ & 224 \\
\hline Postterm & 0 & $1(100.0)$ & 0 & $1(100)$ \\
\hline
\end{tabular}

Symmetric measures of agreement (kappa), value 0.369, Approx. T7.416, p-value=1.20E-13, Agreement is-Significant

Using kappa statistics, the agreement between clinical examination and dating by neonatologists showed "fair" agreement. This signifies relatively more accurate than LMP for dating of pregnancy. (Kappa value of agreement being 0.369 for clinical examination and 0.197 for menstrual dates).

As shown in table 5, 225 patients were considered to be of term gestation at the time of delivery when calculated by ultrasound but when the dating was done by the neonatologist at the time of delivery 213 patients i.e. almost $94.7 \%$ was in the agreement with the term gestation, 8 patients $(3.6 \%)$ who were actually thought to be term were post-dated and $4(1.8 \%)$ were preterm.

The kappa coefficient for the agreement between scan and neonatologist was 0.415 , which indicates a moderate agreement between the two methods of gestational age assessment. Twenty-seven patients at the time of delivery were less than 37 weeks but when dating was done by the neonatologist only $11(40.7 \%)$ were preterm while majority of the babies were of term gestation. Out of 5 patients considered to be post-dated by the ultrasound, dating by neonatologist considered only 2 neonates i.e. 
$40 \%$ of them to be post-dated while the remaining 3 neonates $(60 \%)$ were of term gestation.

Table 5: Correlation of dating by ultrasound with dating by neonatologist.

\begin{tabular}{|lllll|}
\hline & \multicolumn{2}{l}{$\begin{array}{l}\text { Dating by Neonatologist } \\
\text { (Weeks) }\end{array}$} & \\
\cline { 2 - 5 } & $\begin{array}{l}\text { Preterm } \\
(\boldsymbol{\%})\end{array}$ & $\begin{array}{l}\text { Term } \\
(\boldsymbol{\%})\end{array}$ & $\begin{array}{l}\text { Post- } \\
\text { term } \\
(\boldsymbol{\%})\end{array}$ & Total \\
\hline Preterm & $11(40.7)$ & $15(55.6)$ & $1(3.7)$ & 27 \\
\hline Term & $4(1.8)$ & $213(94.7)$ & $8(3.6)$ & 225 \\
\hline Post term & 0 & $3(60.0)$ & $2(40.0)$ & 5 \\
\hline
\end{tabular}

Measure of Agreement (Kappa); Value0.415; Approx. T8.367 p-value5.89E-17; Agreement is-Significant

However, when compared to use of menstrual dates and clinical examination (kappa value being 0.197 and 0.369 respectively), the kappa value for ultrasonography was 0.415 thus it can be interpreted that the accuracy of ultrasonography may be slightly better than menstrual dates and clinical examination. To summarise, it is seen that ultrasonography was accurate for determination of term /preterm/ post-term births followed by clinical examination and then the menstrual EDD.

\section{DISCUSSION}

Out of 260 patients, 221 patients delivered at term gestation when calculated by menstrual history. When the dating of the newborn was done by the neonatologist it was found that 203 patients $(91.9 \%)$ were in agreement with the menstrual history whereas 7 patients i.e. $3.2 \%$ who were considered to be term were actually preterm and $11(5 \%)$ were post term when the dating was done by the neonatologist. This signifies that LMP may be reliable to predict term births.

Out of 28 patients delivered at preterm gestation as calculated by menstrual history, only 9 (32.1\%) were determined to be preterm by the neonatologist.

Out of 11 patients supposed to be post-dated by the menstrual history, none of them were post-dated when estimated by the neonatologist. This shows the inaccuracy of LMP in determining preterm and post term pregnancies. Similarly, in their two-centred study by Medeiros et al, they found a sensitivity of LMP obtained prenatally to estimate preterm birth rate was $65.6 \%$ in one centre and $78.7 \%$ in another centre. The sensitivity and positive predictive value of LMP for the estimate of the post-term birth rate was very low and tended to overestimate it. LMP can be used with some errors to identify preterm births, whereas it was not good to use it to predict post-term births. ${ }^{5}$ In contrast a study done by Rosenberg et al in Bangladesh, using antenatal ultrasound as gold standard, it was found that Ballard scoring and LMP were quite reliable for estimation of gestational age of preterm infants. ${ }^{6}$
In a study done by Neufeld et al in rural areas of developing countries it was found out that gestational age determination by menstrual dating is best when trained personnel help women to recall their LMP. In cases of non-availability of LMP, SFH can also be used as an alternative. $^{7}$

To summarise, the accuracy of LMP in predicting preterm and post term is poor but can be accurate to a predict term gestation.

Among 224 patients who were considered term gestation by clinical examination, $211(94.2 \%)$ were determined to be term by the neonatologist gestation and the remaining $10(4.5 \%)$ were post-dated and $3(1.3 \%)$ determined as preterm gestation.

Out of the 35 patients thought to be delivered at preterm gestation by clinical examination, almost 13 (37\%) were determined to be preterm by the neonatologist. This large number shows that the relative inaccuracy in estimation of preterm status by clinical examination. Such inaccuracies may be partly explained by patient factors such as BMI. Deeluea et al. had shown BMI to be a confounding factor and had suggested that different kind of tapes be used for overweight and underweight women. $^{8}$

Inspite of inaccuracy of clinical examination in predicting preterm births use of SFH in assessment of gestational age is very important in resource-poor settings because their assessment of gestational age is difficult because of poor recall of last menstrual period; there is no ultrasound (US) and non practising of newborn gestational age dating by birth attendants. A study was done in which women attending antenatal care on the Thai-Burmese border were included. They found out that the accuracy depended on the number of SFH measures recorded per mother (for example six SFH measurements resulted in a prediction accuracy of \pm 2 weeks). ${ }^{9}$

To increase the sensitivity of symphysio-fundal height measurement, adjustments have been attempted. Using function of BMI, mean upper arm circumference and parity, adjustments were attempted by Challis et al. These adjustments improved the sensitivity marginally, but at the cost of specificity. ${ }^{10}$ Though there is no conclusive evidence regarding the usefulness of $\mathrm{SFH}$, it continues to be a valuable tool. ${ }^{11}$ In present study also, clinical examination was more accurate than LMP for dating the pregnancy. Kappa value of agreement was 0.369 for clinical examination and 0.197 for menstrual dates. Supporting this a study was done by Ananth et al. in which gestational age assessment by menstrual dating and clinical examination were compared. They found out that clinical estimate should be used in modern obstetrics for gestational age assessment. As compared to menstrual dating clinical assessment leads to decline in both preterm and post-term births. ${ }^{12}$ 
In present study, LMP computed approximately 5\% births to be post-dated while first trimester ultrasound reported none of the pregnancy had reached post-datism. This signifies that first trimester ultrasound helps to prevent unnecessary induction of labor for supposed post datism when calculated by menstrual history.

Similarly, in a study done by Hoffman et al, LMP and first trimester ultrasound scan were compared for pregnancy dating and to study the maternal and infant characteristics. They found out that calculation of gestational age by menstrual history classified more births as post term when compared with the ultrasound. ${ }^{13}$

In present study in a subgroup of patients in which first trimester ultrasound scan was available to date the pregnancy $12 \%$ were preterm according to USG dating and clinical examination whereas $6 \%$ were considered to be preterm by menstrual history.

In contrast, a study was conducted by Ambrose et al to compare the number of preterm births based on obstetric estimates versus LMP estimates, and to evaluate clinical risk indicators associated with prematurity. It was found that more births were $<37$ weeks based on LMP and this was less when based on obstetric estimates. In this study, two groups were compared.

The group of infants which were born as 37-41 weeks by obstetric estimates, had much lesser NICU admission rates, compared to those which were born as <37 weeks based on the same obstetric estimates. The study concluded that assessments of gestational age based on LMP alone may overestimate prematurity incidence by $20 \% .^{14}$

From the findings of present study, we conclude that ultrasonography was most accurate for determination of term /preterm/ post-term births followed by clinical examination and then the menstrual EDD. Thus, in patients who are unregistered, and ultrasound is not available, clinical examination must be done meticulously.

\section{CONCLUSION}

Ultrasonography was found to be accurate for determination of term /preterm/ post-term births followed by clinical examination and then the menstrual EDD. Induction of labor for supposed post-term pregnancy was avoided in $13 \%$ of the patients in whom EDD was "assigned" thus stressing that EDD should be reassigned when there is discrepancy between menstrual EDD, Ultrasonography EDD and EDD by clinical examination.

\section{ACKNOWLEDGMENTS}

The first author would like to acknowledge the contribution of Dr. Madhva Prasad for help in improvement of the manuscript.
Funding: No funding sources

Conflict of interest: None declared

Ethical approval: The study was approved by the Institutional Ethics Committee

\section{REFERENCES}

1. Gagliardi L. On the importance and unimportance of gestational age. Acta Paediatr. 2015;104(6):544-6.

2. van Baaren GJ, Peelen MJ, Schuit E, van der Post JA, Mol BW, Kok M. Preterm birth in singleton and multiple pregnancies: evaluation of costs and perinatal outcomes. Eur J Obstet Gynecol Reprod Biol. 2015; 186:34-41.

3. Enabudoso EJ, Obhielo E. Socio-demographic and obstetric determinants ofgestational age at booking at the University of Benin Teaching Hospital: adescriptive survey. Niger Postgrad Med J. 2012;19(3):149-52.

4. Honest H, Forbes CA, Durée KH, Norman G, Duffy SB, Tsourapas A, et al. Screening to prevent spontaneous preterm birth: systematic reviews of accuracy and effectiveness literature with economic modelling. Health Technol Assess. 200913(43):1627.

5. Medeiros MNL, Cavalcante NCN, Mesquita FJA, Batista RLF, Simões VMF, Cavalli R de C, et al. Validity of pre and post-term birth rates based on the date of last menstrual period compared to early obstetric ultrasonography. Cad saúde pública.2015;31(4):885-90.

6. Rosenberg RE, Ahmed AS, Ahmed S, Saha SK, Chowdhury MA, Black RE, Santosham M, et al, et al. Determining gestational age in a low-resource setting: validity of last menstrual period. J Health Popul Nutr. 2009;27(3):332-8.

7. Neufeld LM, Haas JD, Grajeda R, Martorell R. Last menstrual period provides the best estimate of gestation length for women in rural Guatemala. Paediatr Perinat Epidemiol. 2006;20(4):290-8.

8. Deeluea J, Sirichotiyakul S, Weerakiet S, Arora R, Patumanond J. Fundalheight growth curve for underweight and overweight and obese pregnant women in Thai population. ISRN Obstet Gynecol 2013;2013:657692.

9. White LJ, Lee SJ, Stepniewska K, Simpson JA, Dwell SLM, Arunjerdja R, et al. Estimation of gestational age from fundal height: a solution for resource-poor settings. J R Soc Interface. 2012; 9(68):503-10.

10. Challis K, Osman NB, Nordahl G, BergströmS. The impact of adjustment forparity and mid-upper-arm circumference on sensitivity of symphysis-fundus height measurements to predict SGA foetuses in Mozambique. Trop Med IntHealth. 2003;8(2):16873.

11. Peter JR, Ho JJ, Valliapan J, Sivasangari S. Symphysial fundal height (SFH) measurement in pregnancy for detecting abnormal fetal growth. Cochrane Database Syst Rev. 2015;(9):CD008136. 
12. Ananth C V. Menstrual versus clinical estimate of gestational age dating in the United States: temporal trends and variability in indices of perinatal outcomes. Paediatr Perinat Epidemiol. 2007; 21(S2):22-30.

13. Hoffman CS, Messer LC, Mendola P, Savitz DA, Herring AH, Hartmann KE. Comparison of gestational age at birth based on last menstrual period and ultrasound during the first trimester. Paediatr Perinat Epidemiol. 2008;22(6):587-96.

14. Ambrose CS, Caspard H, Rizzo C, Stepka EC, Keenan G. Standard methods based on last menstrual period dates misclassify and overestimate US preterm births. J Perinatol. 2015;35(6):411-4.

Cite this article as: Singhal N, Gupta AS. An observational study to determine accuracy of various methods used to assign gestational age and correlate with outcome. Int J Reprod Contracept Obstet Gynecol 2018;7:3790-5. 